\title{
High-dose inhaled corticosteroids and add-on therapy use in adults with asthma in the UK in 2003: an observational study
}

\author{
Mike Thomas*, David Leather, David Price
}

\author{
Department of General Practice and Primary Care, University of Aberdeen, \\ Foresterhill Health Centre, Westburn Road, Aberdeen AB25 2AY, Scotland, UK
}

Received 31 October 2005; accepted 21 February 2006

KEYWORDS

Asthma;

Primary care;

Inhaled corticosteroids;

Pharmacosurveillance

\section{Summary}

Aims: To quantify use of high dose inhaled cp tiesterods (ICS) and add-on therapy in adults, and children aged 12 ardover, in the community.

Methods: Cros:-sectibna bsservational sufvev of UK general practice prescribing

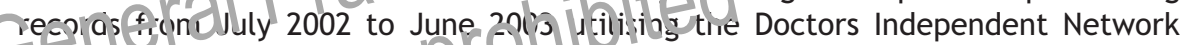
Ilinical database.

Results: 39,695 Gatients aged 12 and over were treated for asthma with inhaled erriccssoroids, with a quantifiable daily dose recommendation in 22,027 cases. Twehty-seven percent (95\% Confidence Intervals 26-28\%) were prescribed 'highdose' ICS (>800 mcg/day beclomethasone or equivalent). Of these, $32 \%(31-33 \%)$ were not currently prescribed add-on therapy (long acting B2 agonists, leukotriene antagonists, theophylines), and most of these $(84 \%, 82-86 \%)$ had never received a prior trial of add-on therapy.

Conclusions: High dose ICS therapy was commonly prescribed to people with asthma, frequently without co-prescribed add-on therapy. Many adults with more severe asthma may be receiving treatment that does not accord with current evidence of best practice.

(c) 2006 General Practice Airways Group. Published by Elsevier Ltd. All rights reserved.

\section{Introduction}

Asthma is a common disease managed principally in the community, is characterised by persistent airways inflammation [1], and is treated by anti-

\footnotetext{
* Corresponding author. Tel.: +44 1453883 793;

fax: +44 1453731670 .

E-mail address: mikethomas@doctors.org.uk (M. Thomas).
}

inflammatory medication. Inhaled corticosteroids (ICS) are the principal anti-inflammatory agents used in persistent asthma [2-4] and have an excellent efficacy and safety profile in moderate doses [5-7]. As well as improving symptoms and lung function [6,7], ICS have been shown to protect against hospitalization [8] and mortality [9]. Due to concerns about the steroid-related adverse events associated with systemic absorption [6] 
at higher doses, guidelines recommend that minimum effective ICS doses are used, and a step-wise approach to asthma pharmacotherapy is advocated [2,3]. Although individual heterogeneity of response to varying doses of ICS has been reported [10], for most patients near-maximum responses to most parameters of control occur at low to medium doses of ICS [10], with the doseresponse relationship plateauing at $800 \mathrm{mcg} / \mathrm{day}$ of beclomethasone propionate or equivalent (beclomethasone and budesonide are considered equipotent, with fluticasone having double potency [11]), even though some patients will benefit from high-dose treatment $[12,13]$.

In spite of effective therapy, many people with asthma continue to suffer from significant symptoms [14,15], and some require higher levels of therapy. Recent evidence has highlighted that outcomes are usually better when add-on therapy is used (with long acting B2 agonists (LABA) for adults and children over five years of age) compared to high-dose ICS use $[16,17]$. Other add-on therapies such as leukotriene receptor antagonists (LTRAs) $[12,18]$ have also been shown to be effective. As a consequence, the latest British asthma guidelines [2] issued in 2003 and summarising the evidence of previous years, recommend that high doses of ICS $(>800 \mathrm{mcg} /$ day beclomethasone or equivalent) should be used cautiously ancion ofter unsuccessful trials of add or thera, iv in addition to

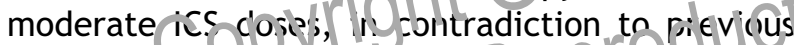
guidelines wrich had stated thay high-dose ICS treatment was a first-choice step-up option [19].

The benefits of high doses of ICS must be balanced against the risks of systemic steroid absorption [6]. Although the side effects of systemic corticosteroids are well recognised, the safety profile of low and moderate doses of ICS is excellent, with very low levels of steroid-related problems in adults using less than $800 \mathrm{mcg} / \mathrm{day}$ of beclomethasone or equivalent $[6,7]$. There is evidence, however, of systemic bioavailability at higher dosages [6,7]. Long-term use of ICS has been associated with a dose-related increased risk of cataract formation [20], glaucoma [21], osteopenia, and hip fracture rate [22], and, when used in unlicensed doses in children, with acute adrenal insufficiency $[23,24]$.

It is not known what proportion of patients treated for asthma in the community are receiving high doses of ICS and what proportion are receiving concomitant add-on therapy or have had prior therapeutic trials. This study aimed to quantify this information in a representative UK general practice population in a cross-sectional survey undertaken at the time of the issue of the latest guidelines. Although it is recognised that the timing of the survey (shortly after the dissemination of the revised BTS guidelines in 2003) means that there would not have been time for general practitioners (GPs) to have changed treatment regimes systematically, this survey aimed to quantify the extent of prescribing not in accord with the latest evidence-based recommendations at that time. The evidence informing these recommendations had been in the public arena for a number of years before the revision of the guidelines, and had received pre-launch publicity in generalist journals and in the general practice press for 12 months prior to full publication, so many GPs would have been aware of the changed evidence base even before the publication and dissemination of the guidelines in 2003. Yet it remained possible that some clinicians had continued to make prescribing decisions based on evidence that had been superseded in more recent years.

\section{Methods}

\section{Study population}

Data for this sicicy Werce taken from the DIN (Doctors ridef(encent Network) clatabase [25], a longitudinal clinical and ples'fing database supplied by UK CDs (17' Complicerised practices using the Torex Heal in Practice software. The database collects deidentified routine clinical data from the electronic clinical and prescribing records of 150 participating UK General Practices serving a population of almost 2 million patients scattered in a geographically representative way through the UK. These patients have representative demographic, diagnostic and consultation profiles to other UK databases such as the GPRD [26]. The clinical software is used by GPs for routine clinical record keeping and for prescribing, and data are extracted for research purposes. Data are monitored for quality and the highest quality data provider practices used in epidemiological research. The database has resulted in over 40 peer-reviewed epidemiological scientific publications. In this study a database of 778,001 patients representative of UK national demographic profiles was used of whom 665,784 patients were aged 12 years old or over on 1.7.03 (see Figure 1).

\section{Pharmacotherapy definitions}

ICS are defined as any inhaled preparation containing a corticosteroid, including combination products. 


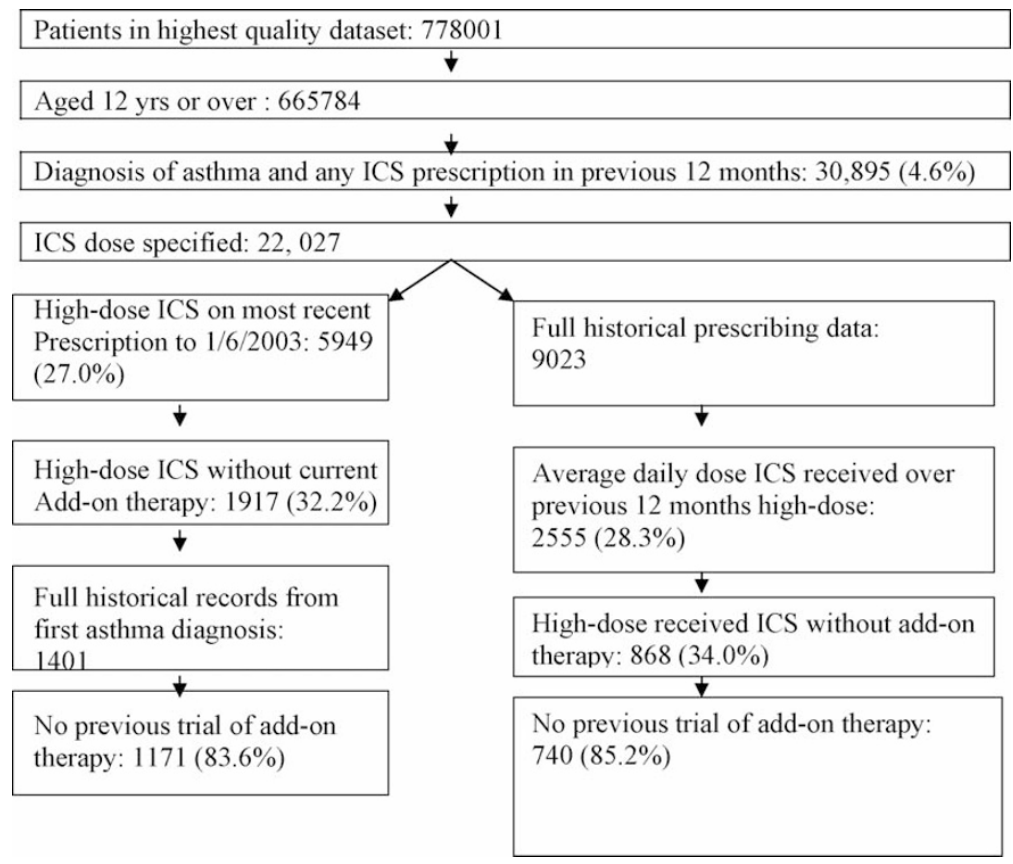

Figure 1 Study flow diagram.

'Add-on therapy' is defined as any inhaled preparation containing a LABA (including combination products), any oral LTRA, any via! theophylline preparation, or any inhaled ch-omone preparation.

'Pres cribedics cicse' is calculated from the to da daily ICS dese specified in the cidsirg instructions on the most recent prescription. Although nonquantifiable dose instructions were present on some prescriptions, the intended daily dose was quantifiable for $71.4 \%$ of subjects.

'High-dose prescribed ICS' is defined as a dose instruction on the latest ICS prescription equating to $>800 \mathrm{mcg} /$ day beclomethasone or equivalent (i.e. $>800 \mathrm{mcg}$ budesonide, $>400 \mathrm{mcg}$ fluticasone).

'Unlicensed prescribed dose ICS' is defined as a dose instruction on the latest ICS prescription equating to $>2000 \mathrm{mcg} /$ day beclomethasone or equivalent.

'High-dose received ICS' is defined in patients with uninterrupted prescribing data as an average daily ICS dose of $>800 \mathrm{mcg} /$ day beclomethasone or equivalent. The average daily dose of inhaled steroid received in the 12-month period from 1st July 2002 to 30th June 2003 was calculated by summating the total dosage of steroid contained in all ICS-containing preparations prescribed over this time to patients with full uninterrupted records divided by 365 .

'Unlicensed received dose ICS' is defined in patients with complete 12 months' prescribing data as an average daily ICS aos of $>2000 \mathrm{mcg} / \mathrm{day}$ beclometh a sone or equivalent.

C' Current co-prescription with add-on therapy' is defined as alisy preocription for any add-on therapy in the perlod from 3 months before to 3 months after the latest ICS prescription up to 1.7.03.

'Current co-receipt of add-on therapy' is defined in patients with uninterrupted 12 months' prescribing data as any prescription for add-on therapy within this time frame.

'Previous trials of add-on therapy' are defined in a minority of patients with full clinical and prescribing information from the time of asthma first diagnosis as any past prescription for add-on therapy.

\section{Data analyses}

The data analysis plan was specified a priori. Descriptive statistics were used to calculate the percentages of patients in the database adult population receiving high and unlicensed doses of inhaled steroids and for the percentages of patients receiving add-on therapy.

\section{Details of ethical approval}

This study used de-identified data generally available from the DIN-Link clinical database. This database is maintained ethically and conforms to the requirements of the Data Protection 
Table 1 Inhaled Corticosteroid (ICS) prescribed dose for asthma treatment and use of add-on therapy

\begin{tabular}{lcc}
\hline & $\begin{array}{c}\text { Number in database } \\
\text { with data }\end{array}$ & $\begin{array}{c}\text { Percentage of all ICS prescription } \\
\text { (95\% Confidence Intervals) }\end{array}$ \\
\hline Known ICS dose & 22027 & 100 \\
High-dose ICS & 5949 & $27.0(26.4-27.6)$ \\
High-dose ICS plus add-on therapy & 4032 & $18.3(17.8-18.8)$ \\
High-dose ICS without add-on therapy & 1917 & $8.7(8.3-9.1)$ \\
\hline
\end{tabular}

Act. Ethical approval was retrospectively gained from the OPCEC (Optimum Patient Care Ethics Committee), an independent ethics committee specialising in database and pharmacoepidemiological studies.

\section{Results}

\section{Population}

665,784 patients were aged 12 years old or over on 1.7.03, and of these 30,859 had both a clinical diagnosis of asthma and had received a prescription for an inhaled corticosteroidcontaining preparation between 1.7 .02 and 30.6 .03 (4.6\% of the eligible population) (Figure 1).

The daily dose was specified in $22,02 \bar{\Delta}$ rotents. In the remaining 8868 patients $1285 \%$, the dosing instructio is were: Vundegar - for exampita. (as directed' crrus not allowing dres guancitication.

\section{High-dose ICS and add-on therapy prescribing on latest prescription}

The dose of ICS recommended on the latest prescribing instructions was 'high-dose' for 5949 of 22027 patients $(27.0 \%$, 95\% Cl $26.4-27.6 \%)$ (Table 1).

Add-on therapy was prescribed in a six-month time window spanning the latest ICS prescription to 4032 patients, indicative of lack of add-on therapy co-prescription in $32.2 \%(95 \% \mathrm{Cl} 31.0-33.4 \%)$ of patients prescribed high-dose ICS. The type of addon therapy used is shown in Table 2.

Full clinical and prescribing records to the time of the original diagnosis of asthma were available in 1401 of the 1917 patients prescribed highdose ICS without current co-prescription of add-on therapy; in these patients, evidence of a previous prescription of any add-on therapy at any time was found in 230 , so $83.6 \%$ (95\%, $\mathrm{Cl} 81.7-85.5 \%)$ had never received a trial of add-on therapy.

\section{High-dose ICS and add-on therapy receipt over the previous 12 months' prescribing data}

Due to the movemengilpatiens between general prasticesaninteriptions in the continuity of data held in medical record., full historical data since the time of cilist astama diagnosis was only present in 9123 : Patents (29\%). Of the 9023 patients with full uninterrupted data from the time of asthma diagnosis, the average daily dose received over the previous 12-month period was high in 2555 $(28.3 \%, 27.4-29.2 \%)$ (Table 3). Of these patients, no prescription for any add-on therapy was received in the previous 12 months by 868 (34.0\%, 32.2-35.8\%), and of these patients prior prescriptions of addon therapy indicating a previous trial of treatment were found in only 128 , indicating that $85.3 \%$ (95\% $\mathrm{Cl} 83.0-87.6 \%$ ) had never had a trial of add-on therapy.

The average daily ICS dose received was high enough to be above licensed use in 317 patients $(3.5 \%, 3.1-3.9 \%)$.

Table 2 High-dose Prescribed Inhaled Corticosteroid (ICS) and Add-on Therapy (Long acting beta 2 agonist (LABA), Leucotriene Receptor Antagonist (LTRA) or Xanthine preparations) on most recent prescription

\begin{tabular}{|c|c|c|}
\hline & $\begin{array}{l}\text { Number in database } \\
\text { with data }\end{array}$ & $\begin{array}{l}\text { Percentage ( } 95 \% \\
\text { Confidence Intervals) }\end{array}$ \\
\hline High-dose ICS & 5949 & 100 \\
\hline High-dose ICS + LABA & 3474 & $63.2(61.9-64.5)$ \\
\hline High-dose ICS + LTRA & 271 & $4.9(4.3-5.5)$ \\
\hline High-dose ICS + Xanthine or chromone & 287 & $5.2(4.6-5.8)$ \\
\hline High-dose ICS, no add-on & 1917 & $32.2(31.0-33.4)$ \\
\hline
\end{tabular}


Table 3 Inhaled Corticosteroid (ICS) dose receipt and add-on therapy over the previous 12 months

\begin{tabular}{llc}
\hline & Number in database & $\begin{array}{c}\text { Percentage }(95 \% \\
\text { Confidence Intervals) }\end{array}$ \\
\hline Known ICS dose & 9023 & 100 \\
High-dose ICS & 2555 & $28.3(27.4-29.2)$ \\
High-dose ICS without add-on therapy & 868 & $9.6(9.0-10.2)$ \\
Unlicensed dose ICS & 317 & $3.5(3.1-3.9 \%)$ \\
\hline
\end{tabular}

Received ICS dose and add-on therapy over 12 month period up to June 2003.

\section{Discussion}

These data indicate widespread use of high dose inhaled corticosteroid treatment, frequently without add-on therapy, in the treatment of asthma in the UK in 2003. One quarter of all adults and children aged 12 years or over were recommended high doses of ICS on their most recent ICS prescription. Since non-compliance and under-use of recommended doses of ICS may occur, in those with full records since the date of asthma diagnosis we analysed the total ICS load received over a 12-month period, observing a similar proportion exposed to high ICS doses. One third were not receiving add-on therapy and most had never had a prior trial of add-on therapy. The use of very high and potentially dangerous doses of ICS was found in one in 20 gatients. Given the high prevalence of Teated' asthma in the community these findings indicate that arg= numbers of pacients were receiving the apy out of accord with current evidence of best treatment as summarised in the recently published BTS asthma guidelines. The analysis was made at the time of the 2003 BTS guidelines revision, which recommended add-on therapy before high-dose ICS use, and the body of evidence supporting this recommendation had been in the public arena for some years. Older guidelines had stated that high-dose ICS use was an alternative option, and it seems likely that some prescribers had failed to change their prescribing in line with the new evidence of best practice.

This study utilised a large UK clinical database extensively used in epidemiological surveys, but there are weaknesses inherent in such data. The diagnosis of asthma is physician-applied, and misdiagnosis may occur $[27,28]$. In this study there is no information on the objectivity of diagnosis. Although the prescribing data is an accurate record of issued prescriptions, it is not possible to confirm that the prescription resulted in the collection of a dispensed inhaler device, or the extent of use of the device. There is evidence of poor compliance with ICS treatment $[29,30]$, although this would be expected to be reflected in a lack of issued ICS prescriptions [31,32].

The recommendation that add-on therapy should be tried before high-dose ICS, is highlighted as one of the 'key messages' in the current UK guidelines [2]. As a heterogeneous condition, no single treatment will suit all patients, and some uncontrolled patients will benefit from higher doses of ICS $[11,12]$. Current consensus of best practice indicates that a dose of ICS above $800 \mathrm{mcg} / \mathrm{day}$ should not be used without a previous trial of add-on therapies, and that ICS dose is 'stepped down' when good control has been achieved. An appropriate step down strategy nay lead to lower steroid dosage exoo:urre witnout a loss of control [337, and incroauction of a LABA [34] or a $L$ R. $[35,36]$ may allow for ICS dose reduction without los's of ic nefol. A recent study on patients receiv n, high dose ICS similarly showed that a stepdo $n$ approach allowed dose reduction without compromising asthma control [37]. These studies indicate that some patients are maintained on unnecessarily high doses of ICS.

Our 'real-word' observational data are consistent with these suggestions. The finding in this study of widespread use of high-dose ICS, often without concomitant add-on therapy, points to a need for GPs to audit their use of ICS treatment. We recommend that all patients who are receiving high doses of ICS should be reviewed. Stepping down of the ICS dose should be considered in stable patients, and the addition of add-on therapy with a view to ICS dose reduction considered where appropriate. This cross-sectional survey was undertaken at a time shortly after the publication of the BTS/SIGN guidelines, and indicates that many patients were not receiving treatment in accord with the latest recommendations. There is now a need for further analyses of changes in prescribing patterns using more recent data to see whether prescribing is changing in line with current guidelines.

In summary, this analysis of GP prescribing for the treatment of asthma in adults and children aged 12 years or older in the UK in 2003 found significant 
use of high-dose inhaled corticosteroids, often in the absence of add-on therapy or a prior trial of add-on therapy. Many adults with more severe asthma may be receiving treatment that does not accord with current best practice.

\section{Conflict of interests}

Dr. Mike Thomas either through his role at the University of Aberdeen or personally has received grants, honoraria or educational support from the following pharmaceutical companies as well as the UK NHS R\&D programme:

Altana, AstraZeneca, GlaxoSmithKline, Ivax, Merck, Sharpe and Dohme, Schering Plough, Trinity Pharmaceuticals, Viatris.

He does not possess any pharmaceutical shares. $\mathrm{He}$ is a medical advisor to the charity Asthma UK.

Dr David Leather is employed by GlaxoSmithKline UK as a medical advisor. He does not possess any pharmaceutical shares.

Professor David Price either through his role at the University of Aberdeen or personally has received grants, honoraria or educational support from the following pharmaceutical companies as well as the UK NHS R\&D programme:

Altana, AstraZeneca, GlaxoSmithKline, Ivax, Merck, Sharpe and Dohme, Novartis, Schering Plough, Trinity Pharmaceuticals, Viatris.

This study was funded oy anofult atrom GlaxoSmithKline.

\section{Authors' contributions}

MT and DP had the original idea for the study. All authors were involved in the protocol, data analysis and production of the manuscript. MT acts as guarantor.

\section{References}

[1] International consensus report on the diagnosis and treatment of asthma. Eur Respir J 1992;5:601-41.

[2] British Thoracic Society, Scottish Intercollegiate Guideline Network. British Guidelines on the Management of Asthma. Thorax 2003;58:1-94.

[3] Global Initiative for Asthma (GINA). Asthma management and prevention. NIH Publication No. 96-3659A. 1995. Bethesda, Maryland, NHLBI.

[4] Barnes PJ, Pedersen S, Busse WW. Efficacy and safety of inhaled corticosteroids: new developments. Am J Respir Crit Care Med 1998;157:S1-S53.

[5] Barnes PJ. Current issues for establishing inhaled corticosteroids as the antiinflammatory agents of choice in asthma. J Allergy Clin Immunol 1998;10: S427-33.

[6] Lipworth BJ. Systemic adverse effects of inhaled corticosteroid therapy: a systematic review and metaanalysis. Arch Intern Med 1999;159:941-4.
[7] Pedersen S, O'Byrne P. A comparison of the efficacy and safety of inhaled corticosteroids in asthma. Allergy 1997;52(suppl 39):1-34.

[8] Suissa S, Ernst P, Kezouh A. Regular use of inhaled corticosteroids and the long term prevention of hospitalisation for asthma. Thorax 2002;57:880-4.

[9] Suissa S, Elphick HE, Benayoun S, Baltzan M, Cai B. Lowdose inhaled corticosteroids and the prevention of death from asthma. N Eng J Med 2000;343:332-6.

[10] Szefler S, Martin RJ, King TS, et al. Significant variability in response to inhaled corticosteroids for persistent asthma. J Allergy Clin Immunol 2002;109:410-8.

[11] Adams N, Bestall J, Jones P. Beclomethasone at different doses for chronic asthma. The Cochrane Database of Systematic Reviews 1999, Issue 4. Art. No. CD002879, doi:10.1002/14651858.CD002879.

[12] Price D, Hernandez D, Magyar P, et al. Randomised controlled trial of montelukast plus inhaled budesonide versus double dose inhaled beclomethasone in adult patients with asthma. Thorax 2003;58:211-6.

[13] Bateman ED, Boushey H, Busse WW, Clark TJH, Pauwels RA, Pedersen S. Can Guideline-defined Asthma Control Be Achieved? Am J Respir Crit Care Med 2004;170:836-44.

[14] Price D, Ryan D, Pearce L, Bride F. The AIR study: asthma in real life. Asthma J 1999;4:74-8.

[15] Rabe KF, Vermeire PA, Soriano JB, Maier WC. Clinical management of asthma in 1999: the Asthma Insights and Reality in Europe (AIRE) study. Eur Respir J 2000;16: 802-7.

[16] Shrewsbury S, Pyke S, Britton M. Meta-analysi: Of increased dose of inhaled stercid ers acdition of salmeterol in symptomat ic ats thmis (M.A. MA). BMJ 2000;320:1368-73.

$17 \mathrm{KFS} \pi$, Pauwels RA. Long acting inhaled beta 2 agonist therapy in as nina. Am J Respir Crit Care Med $2001 \cdot 1 \leqslant 4$ 9? $3-32$. L

[ic] $\mathrm{L}, \mathrm{j} \in \mathrm{rmar}$ [, Bisgaard $\mathrm{H}$, Bousquet $\mathrm{J}$, et al. Montelukast and fluticasone compared with salmeterol and fluticasone in protecting against asthma exacerbation in adults: one year, double blind, randomised, comparative trial. BMJ 2003;327:891-900.

[19] British Thoracic Society, The National Asthma Campaign, The Royal College of Physicians of London. The British guidelines on asthma management: 1995 review and position statement. Thorax 1996;52(Suppl 1):S1-S21.

[20] Cumming RG, Mitchell P, Leeder SR. Use of inhaled corticosteroids and the risk of cataracts. $N$ Eng $\mathrm{J}$ Med 1997;337:8-14.

[21] Garbe E, LeLorier J, Boivin JF. Inhaled and nasal glucocorticoids and the risk of occular hypertension or open-angled glaucoma. JAMA 1997;277:722-7.

[22] Hubbard RB, Smith CJP, Smeeth L, Harrison TW, Tattersfield AE. Inhaled Corticosteroids and Hip Fracture. A Populationbased Case-Control Study. Am J Respir Crit Care Med 2002;166:1563-6.

[23] Todd GRD, Acerini CL, Ross-Russell R, Zahra S, Warner JT, MCCance D. Survey of adrenal crisis associated with inhaled corticosteroids in the United Kingdom. Arch Dis Child 2002;87:457-61.

[24] Drake AJ, Howells RJ, Shield JPH, et al. Lesson of the week: Symptomatic adrenal insufficiency presenting with hypoglycaemia in children with asthma receiving high dose inhaled fluticasone propionate. BMJ 2002;324:1081-3.

[25] DIN-Link database, Compufile Ltd. www.compufile.co.uk. 2004.

[26] Carey IM, Cook DG, de Wilde S, et al. Developing a large electronic primary care database (Doctors Independent Network) for research. Int J Med Inf 2004;73:443-53. 
[27] Price D, Duerden M. Chronic obstructive pulmonary disease - the lack of a national service framework should not allow us to ignore it. BMJ 2003;326:1046-7.

[28] Thomas M, Price $D$. The diagnosis and assessment of asthma in primary care. In: Scadding G, O'Connor B, editors. Key Advances in the Clinical Management of Asthma. London: The Royal Society of Medicine Press Ltd; 2004.

[29] Juniper EF. The impact of patient compliance on effective asthma management. Curr Opin Pulm Med 2003;9:S8-S10.

[30] Milgrom H, Bender B, Ackerson L, Bowry P, Smith B. Noncompliance and treatment failure in children with asthma. J Allergy Clin Immunol 1996;96:1051-7.

[31] Stoloff SW, Stempel DA, Mayer J, et al. Improved refill persistence with fluticasone propionate and salmeterol in a single inhaler compared with other controller therapies. J Allergy Clin Immunol 2004;113:245-51.

[32] Suissa S, Ernst P. Inhaled corticosteroids: Impact on asthma morbidity and mortality. J Allergy Clin Immunol 2001;107:937-44.
[33] Haahtela T, Jarvinnen M, Kava T, et al. Effects of reducing or discontinuing inhaled budesonide in patients with mild asthma. N Eng J Med 1994;331:700-5.

[34] Price D, Dutchman D, Mawson A, Bodalia B, Duggan S, Todd P. Early asthma control and maintenance with eformoterol following reduction of inhaled corticosteroid dose. Thorax 2002;57:791-8.

[35] Price D, Rouleau MY, Fletcher CP, et al. Use of Montelukast in Tapering Inhaled Corticosteroid Therapy: An Open-Label. 48-Week Trial. Current Therapeutic Research 2001;62: 11.

[36] Lofdhal CG, Reiss TF, Leff J, et al. Randomised placebo controlled trial of effect of a leukotriene receptor antagonist, montelukast, on tapering inhaled corticosteroids in asthmatic patients. BMJ 1999;319:87-90.

[37] Hawkins G, MCMahon AD, Twaddle S, Wood SF, Ford I, Thomson NC. Stepping down inhaled corticosteroids in asthma: randomised controlled trial. BMJ 2003;326: 1115.
Available online at www.sciencedirect.com

science@irect.

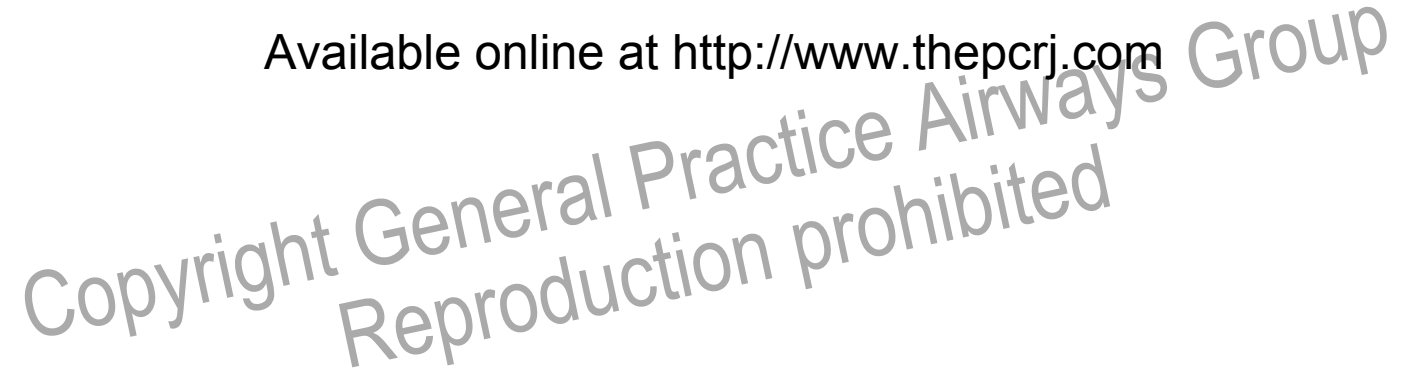

